\title{
EX VIVO BIOMECHANICAL EVALUATION OF THE CANINE CRANIAL CRUCIATE LIGAMENT DEFICIENT STIFLE WITH VARYING ANGLES OF STIFLE JOINT FLEXION AND AXIAL LOADS AFTER TIBIAL TUBEROSITY ADVANCEMENT
}

A Thesis Presented in Partial Fulfilment of the Requirements for The Degree of Master in Science in the Graduate School of The Ohio State University

\section{By}

Daniel E. Hoffmann, DVM

The Ohio State University

2009

Master's Examination Committee:

Approved by

Dr. Jonathan Dyce, Advisor

Dr. Michael Kowaleski

Advisor

Dr. Christopher Adin

Graduate Program in

Veterinary Clinical Sciences 



\section{ABSTRACT}

The tibial tuberosity advancement (TTA) procedure was designed to stabilize the cranial cruciate ligament (CrCL) deficient stifle by advancing the insertion of the patellar tendon cranially. This in turn neutralizes cranial tibial thrust force (CrTT) and prevents cranial tibial subluxation (CTS) during weight bearing. Previous biomechanical investigations have proven that TTA prevents tibial subluxation at a standing angle of $135^{\circ}$ stifle extension with a $30 \%$ body weight axial load applied. No one has investigated the effects of other stifle angles and axial loads as well as the effects of TTA upon retropatellar force (RPF), patellar tendon load (PTL) and patellar tendon angles (PTA).

The purpose of this study was to evaluate the effect of varying stifle angulation and axial loads in the CrCL deficient stifle after TTA on CrTT, RPF, PTL, and patellar PTA as determined by the tibial plateau angle method $\left(\mathrm{PTA}^{\mathrm{TPA}}\right)$ and the common tangent method $\left(\mathrm{PTA}^{\mathrm{CT}}\right)$ in the canine $\mathrm{CrCL}$ deficient stifle joint. We hypothesized that TTA would neutralize CrTT at both stifle angles and with both loads applied. Also, we hypothesized that RPF and 
PTL will be decreased with TTA in all groups. We believed that mean PTA ${ }^{\text {TPA }}$ would be similar to mean $\mathrm{PTA}^{\mathrm{CT}}$ within and among groups. Furthermore, we hypothesized that mean $\mathrm{PTA}^{\mathrm{TPA}}$ and mean $\mathrm{PTA}^{\mathrm{CT}}$ would be equivalent to $90^{\circ}$ in any group and that $\mathrm{PTA}^{\mathrm{CT}}$ would be systematically smaller and less variable than $\mathrm{PTA}^{\mathrm{TPA}}$ in all conditions.

Stifle joints were subjected to differing loading conditions using a constrained limb press model. The CrCL was transected in situ under load. Force sensors allowed direct measurement of CrTT, RPF and PTL. Lateral radiographic projections were used to assess the $\mathrm{PTA}^{\mathrm{TPA}}$ and $\mathrm{PTA}^{\mathrm{CT}}$. Descriptive statistics were used to report CrTT (by design this force returned to zero point values, defined as the neutral point of advancement - NPA). At the NPA, RPF was compared to baseline using a two-tailed sign test. PTL comparisons within groups were performed utilizing a paired t-test. Pair-wise comparisons of $\mathrm{PTA}^{\mathrm{TPA}}$ and $\mathrm{PTA}^{\mathrm{CT}}$ were performed utilizing a paired t-test. Comparisons between loading conditions were made with a one-way ANOVA and post hoc Tukey's test. Equivalence tests were used to test mean PTA ${ }^{\mathrm{TPA}}$ and $\mathrm{PTA}^{\mathrm{CT}}$ for equivalence to $90^{\circ}$. Significance was set at a p-value of 0.05 .

CrTT returned to baseline values, and RPF and PTL were reduced below baseline values in all specimens in a near linear fashion with TTA. At the NPA, $\mathrm{PTA}^{\mathrm{TPA}}>\mathrm{PTA}^{\mathrm{CT}}$ in two of the 3 loading conditions, but there was insufficient evidence to suggest they differed in the third. Mean $\mathrm{PTA}^{\mathrm{TPA}}$ and PTA ${ }^{\mathrm{CT}}$ varied between loading conditions. The threshold for each of the groups evaluated, at 
which the PTA could be significantly different from $90^{\circ}$, was larger for PTA ${ }^{\text {TPA }}$ than $\mathrm{PTA}^{\mathrm{CT}}$ in all groups, as greater variation was observed with $\mathrm{PTA}^{\mathrm{TPA}}$ versus $\mathrm{PTA}^{\mathrm{CT}}$.

This study further supports the claim that reduction of CrTT occurs after TTA in the CrCL deficient stifle joint through an alteration of PTA. Additionally, RPF and PTL also decrease after TTA. The PTA ${ }^{\mathrm{CT}}$ may be more accurate than $\mathrm{PTA}^{\mathrm{TPA}}$ at reflecting the true PTA.

TTA can stabilize the CrCL deficient stifle joint while effectively reducing both RPF and PTL, the latter of which may have a further beneficial effect in protecting intra- and periarticular structures. The PTA ${ }^{\mathrm{CT}}$ method appears to be less influenced by alterations in stifle joint flexion angle than $\mathrm{PTA}^{\mathrm{TPA}}$, and may be the preferred technique for preoperative planning. 


\section{ACKNOWLEDGEMENTS}

The author would like to thank Dr.'s Michael Kowaleski, Randy Boudrieau and Kenneth Johnson for their involvement and dedication with planning and performing the study as well as developing the manuscript. The author also thanks Dr. Rich Evans for statistical analysis and recommendations.

The author thanks Tim Vojt (Medical Illustration and Computer Graphics, College of Veterinary Medicine, The Ohio State University, Columbus, OH) for the three-dimensional computer graphics of the stifle joint.

The author would also like to thank The Ohio State University Canine Research Fund Grant and the Fund for Companion Animal Health from the Cummings School of Veterinary Medicine at Tufts University for the funding to perform the study. 


\section{VITA}

Born.

1995-1999

2000-2004

2004-2005

vi
October 4, 1976

Bachelor of Science,

Saint Vincent College,

Latrobe, PA

Doctor of Veterinary Medicine,

University of Minnesota,

College of Veterinary Medicine,

St. Paul, MN

Internship, Small Animal Medicine

and Surgery, Virginia-Maryland

Regional College of Veterinary

Medicine, Blacksburg, VA 
Internship, Small Animal Surgery,

Dallas Veterinary Surgical Center,

Dallas, TX

2006-2009

\author{
Residency, Small Animal Surgery, \\ The Ohio State University, College \\ of Veterinary Medicine, \\ Columbus, $\mathrm{OH}$
}

\title{
PUBLICATIONS
}

1. Hoffmann DE, Miller JM, Ober CP, Lanz OI, Martin RA, Shires PK. Tibial tuberosity advancement in 65 canine stifles. Vet Comp Orth Traum, 2006;19(4):219-227

2. Thomson SM, Kennerly E, Olby N, Mickelson JR, Hoffmann DE, Dickinson PJ, Gibson G, Breen M. Microarray analysis of differentially expressed genes of primary tumors in the canine central nervous system. Vet Pathol, 2005;42(5):550-8 
3. Hoffmann DE, Tobias AH. What is your diagnosis? Cor triatriatum dexter. J Am Vet Med Assoc, 2003;223(7):951-2

4. Roberts MC, Hitte C, Hendrickson JA, Hoffmann DE, Flickinger GH, Rutherford MS, Andre C, Galibert F, Mickelson JR. Characterization and radiation hybrid mapping of expressed sequence tags from the canine brain. Mamm Genome, 2003;14(3):203-13

\title{
FIELDS OF STUDY
}

\author{
Major Field: $\quad$ Veterinary Clinical Sciences \\ Specific Field: $\quad$ Veterinary Small Animal Surgery
}




\section{LIST OF FIGURES}

FIGURE 1. LIMB PRESS APPARATUS ........................... 25

FIGURE 2. CRANIAL TIBIAL SUBLUXATION

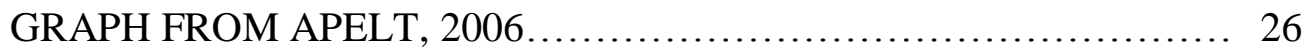

FIGURE 3. PATELLAR TENDON ANGLE GRAPH

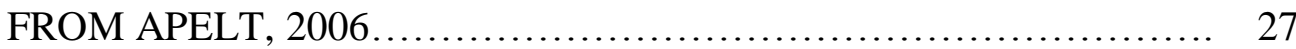

FIGURE 4. PATELLAR TENDON ANGLE

MEASUREMENT METHODS..................................... 28

FIGURE 5. LINE GRAPHS OF GROUP 1

MEANS FOR CRANIAL TIBIAL THRUST,

RETROPATELLAR FORCE AND PATELLAR

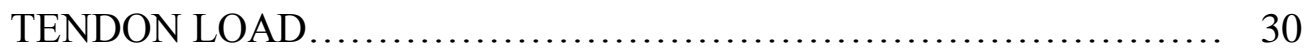


FIGURE 6. LINE GRAPHS OF SPECIMEN 2 FOR

CRANIAL TIBIAL THRUST, RETROPATELLAR

FORCE AND PATELLAR TENDON LOAD ......................... 32

FIGURE 7. PRACTICAL EQUIVALENCE BY

GROUP FOR PATELLAR TENDON ANGLE ........................ 33

FIGURE 8. PRACTICAL EQUIVALENCE

OF ALL SAMPLES FOR PATELLAR TENDON

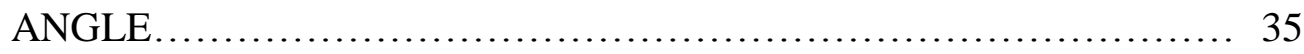

FIGURE 9. GRAPHICAL DEPICTION OF

VARIANCES FOR PATELLAR TENDON ANGLE.................. 36

FIGURE 10. SPRING TENSION EFFECT .......................... 37 
TABLE OF CONTENTS

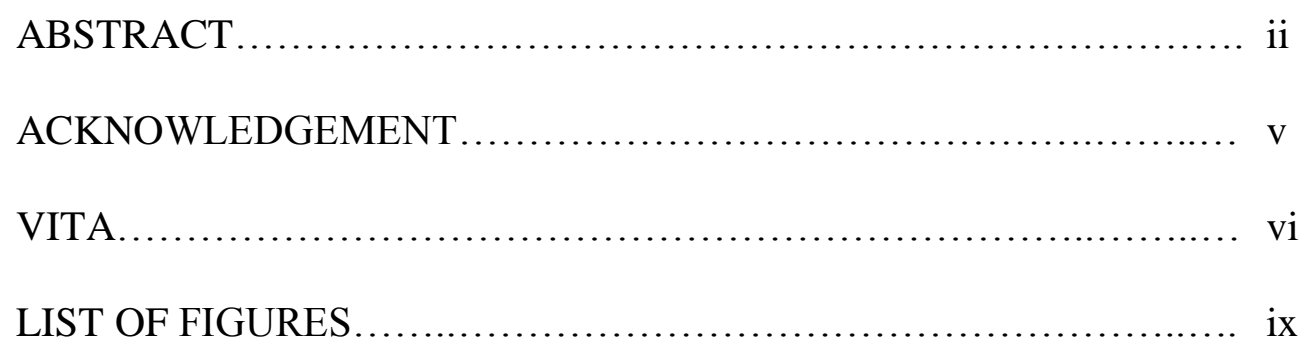

\section{CHAPTERS:}

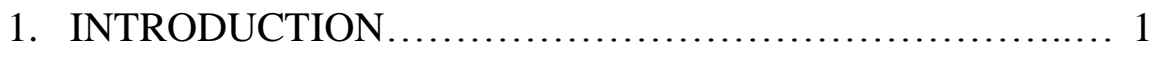

a. CRANIAL CRUCIATE LIGAMENT

RUPTURE PATHOPHYSIOLOGY .................... 1

b. PREVIOUS SURGICAL TREATMENT

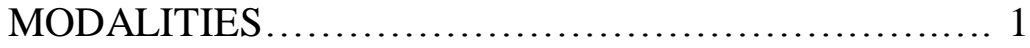

c. TIBIAL TUBERSOITY ADVANCEMENT

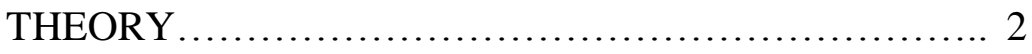

d. PREVIOUS BIOMECHANICAL STUDIES .......... 4

e. HYPOTHESES ................................... 7 
2. MATERIALS AND METHODS ............................ 8

a. LIMB PREPARATION ............................. 8

b. BIOMECHANICAL TESTING...................... 10

c. DATA COLLECTION AND ANALYSIS.............. 13

d. STATISTICAL ANALYSIS .......................... 13

3. RESULTS ............................................. 15

a. CRANIAL TIBIAL THRUST FORCE............... 15

b. RETROPATELLAR FORCE......................... 15

c. PATELLAR TENDON LOAD........................ 15

d. PTA .............................................. 16

i. TRADITIONAL METHOD..................... 16

ii. COMMON TANGENT METHOD.............. 16

4. DISCUSSION .............................................. 18

a. CRANIAL TIBIAL THRUST FORCE................. 19

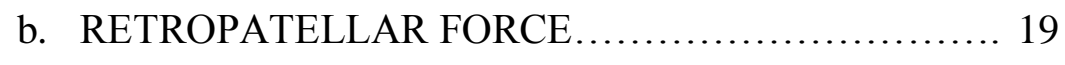

c. PATELLAR TENDON LOAD ......................... 20

i. SPRING TENSION EFFECT .................... 20

ii. RAW DATA CORRECTION................... 21

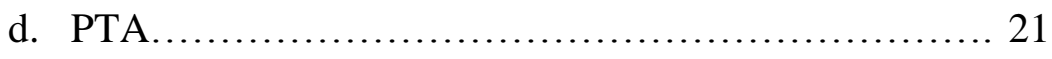

i. TRADITIONAL METHOD ..................... 21

ii. COMMON TANGENT METHOD.............. 21

5. CONCLUSION ........................................... 23 


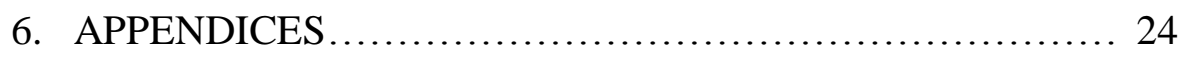

a. LIMB PRESS APPARATUS.......................... 25

b. CRANIAL TIBIAL SUBLUXATION

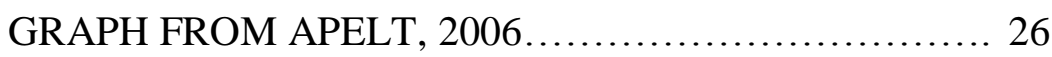

c. PATELLAR TENDON ANGLE

GRAPH FROM APELT, $2006 \ldots \ldots \ldots \ldots \ldots \ldots \ldots \ldots \ldots . \ldots . \ldots \ldots$

d. PATELLAR TENDON ANGLE

MEASUREMENT METHODS............................ 28

e. LINE GRAPHS OF GROUP 1 MEANS

FOR CRANIAL TIBIAL THRUST,

RETROPATELLAR FORCE AND

PATELLAR TENDON FORCE $\ldots \ldots \ldots \ldots \ldots \ldots \ldots \ldots \ldots . \ldots$

f. LINE GRAPHS OF SPECIMEN 2 FOR

CRANIAL TIBIAL THRUST, RETROPATELLAR

FORCE AND PATELLAR TENDON LOAD............. 32

g. PRACTICAL EQUIVALENCE BY GROUP

FOR PATELLAR TENDON ANGLE.................... 33

h. PRACTICAL EQUIVALENCE OF ALL

SAMPLES FOR PATELLAR TENDON

ANGLE ............................................... 35

i. GRAPHICAL DEPICTION OF VARIANCES

FOR PATELLAR TENDON ANGLE................... 36 
j. SPRING TENSION EFFECT.......................... 37

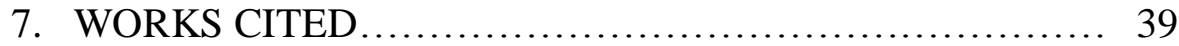

xiv 


\section{CHAPTER 1}

\section{INTRODUCTION}

Cranial cruciate ligament rupture is one of the most common orthopedic diseases seen in the dog. ${ }^{1-3}$ The cranial cruciate ligament $(\mathrm{CrCL})$ has three passive functions in the canine stifle: 1) prevent cranial tibial subluxation, 2) limit internal rotation of the tibia relative to the femur and 3) prevent hyperextension of the stifle. ${ }^{4}$ The CrCL ruptures by one of two mechanisms: 1) acute trauma, usually hyperextension or 2) during normal activity due to gradual ligament deterioration of a yet unidentified process. ${ }^{6}$ The $\mathrm{CrCL}$ deficient stifle suffers instability and cranial tibial subluxation $(\mathrm{CTS})^{5}$ leading to pain, inflammation and osteoarthrosis. ${ }^{4,7}$

There have been many techniques described and applied clinically to treat $\mathrm{CrCL}$ rupture in dogs. These are divided into procedures designed to reconstruct the ligament itself or its function (intra and extracapsular repair) and ones that redirect forces within the joint to neutralize the destabilizing forces. The latter has, until recently, only consisted of two procedures: 1) the tibial 
plateau leveling osteotomy (TPLO) which rotates the tibial plateau to redirect cranial thrust, the destabilizing force according to Slocum, to an axial or caudally directed force ${ }^{8}$ and 2) its predecessor, the cranial closing wedge ostectomy (CCWO) which achieves the same outcome by removing a wedge of bone from the cranial aspect of the proximal tibia. ${ }^{10}$ Good clinical results have been attained with the TPLO ${ }^{9,11}$, but complication rates as high as $25 \%$, that include tibial fracture, meniscal injury, patellar tendonosis and progression of osteoarthrosis, have been reported..$^{9,11-13}$ The CCWO was designed as an adjunct to intracapsular repairs and was found to suffer from significant complications including limb shortening. ${ }^{10}$ The Tibial Tuberosity Advancement (TTA) was clinically introduced as an alternative to the TPLO for treatment of CrCL rupture in dogs by Tepic and Montavon in 2002. ${ }^{6,14-16}$

Advancement of the tibial tuberosity first described by Maquet was based upon the premise that it would increase the efficiency of the quadriceps mechanism and in turn decrease retropatellar force (RPF), thus alleviating pain associated with the patellofemoral joint. ${ }^{17}$ Until recently, other possible effects on the biomechanics of the tibiofemoral joint were not investigated, despite evidence published that a variable tibiofemoral shear force was present in the knee joint; i.e., either anteriorly or posteriorly directed dependent upon the angle of knee joint extension or flexion (and patellar tendon angle - PTA), respectively. ${ }^{18}$ A number of biomechanical studies in humans have demonstrated an increase in translational knee joint instability by variation with tibial plateau 
slope, ${ }^{19,20}$ axial loading, ${ }^{20,21}$ and flexion knee angle ${ }^{.20,22}$ It recently has been shown in a 3-D nonlinear finite element model of the human knee that the Maquet procedure, in addition to decreasing RPF, also was effective in decreasing the femorotibial contact forces in stifle joint extension; similarly, changes in the tibiofemoral shear forces were noted depending upon the knee flexion angle that placed more or less stress on the $\mathrm{CrCL}$ and $\mathrm{CaCL}$ depending upon the amount of tibial tuberosity advancement. ${ }^{23}$ Finally, the quadriceps lever arm also was affected whereby advancing the tibial tuberosity decreased the patellar tendon load (PTL). ${ }^{23,24}$ Taken together, these articles suggest a relationship between tibial tuberosity advancement, PTA, CrTT, RPF (including femorotibial contact forces) and PTL.

Based upon the Maquet procedure ${ }^{17}$ and the data published by Nisell ${ }^{18}$, it was proposed by Montavon and Tepic in $2002^{6,14}$ that a similar situation probably existed in the dog, and advancement of the tibial tuberosity would neutralize CrTT in a CrCL deficient stifle joint in the dog. The point at which there existed a neutral tibiofemoral shear force, as determined by the PTA, was termed the crossover point in this human mechanical model, ${ }^{22}$ and a similar assumption was made for the dog. ${ }^{14}$ It was proposed that moving the tibial tuberosity cranially in the dog's stifle joint, that at full stifle joint extension during weight-bearing $\left(\sim 135^{\circ}\right)$ that the change in the PTA resulted in either a neutral (crossover point) or caudal tibiofemoral shear force. ${ }^{14}$ Thus, in a CrCL deficient stifle joint, the elimination of CrTT would stabilize the joint. ${ }^{14}$ The 
result of these assumptions was the development of the tibial tuberosity advancement (TTA) for treatment of the CrCL deficient stifle joint in the dog. ${ }^{25}$ These assumptions have since been validated in 3 experimental models. ${ }^{26-28}$ These studies evaluated CTS as a measure of CrTT; nonetheless, the latter was not assessed directly. In addition, these investigations examined only a single joint flexion angle and load.

One such study examined basic in vitro biomechanics. ${ }^{26}$ Ten cadaveric limbs were harvested from similarly sized mixed breed dogs free of orthopedic disease. The limbs were prepared by removing all soft tissue except for stifle and tarsus joint elements. The quadriceps mechanism and gastrocnemius muscles were simulated using springs attached at the muscular origins and insertions. The limbs also were marked with radiopaque fiduciary markers on the femur, tibia, third metatarsal and origin and insertion of the medial collateral ligament in order to track bone movement during axial loading. A custom made limb press apparatus was constructed and the limbs were mounted at a standing angle after potting in an aluminum tube (Figure 1). The limbs were then axially loaded at $30 \%$ of body weight. A mediolateral radiograph was made after each loading cycle. This was repeated after medial arthrotomy and transection of the CrCL and then after performing TTA with a commercially available equipment. The fixation plate used to maintain the advancement was custom made to be adjustable using a set screw to allow various advancements. The screw was adjusted one revolution, with the axial load applied and a radiograph was made. 
This process was repeated from maximal advancement until cranial tibial subluxation was achieved. The radiographs were digitized and analyzed for the following variables: 1) tibial plateau angle (TPA), 2) stifle and tarsus joint angle, 3) patellar tendon angle (PTA), 4) distance between the tibial crest and the remaining shaft of the tibia (Ti - TT) and 5) cranial tibial subluxation (CTS). ${ }^{26}$

The mean TPA for all limbs was $26.2^{\circ}$. This is similar to previously reported values for TPA in dogs with CrCL rupture. ${ }^{29,30}$ The CTS for intact CrCL stifles was considered zero. The mean CTS for CrCL deficient stifles was $11.1 \pm 3.4 \mathrm{~mm}$ which was statistically significant, thus verifying the role of the CrCL in joint stability in the cranial caudal direction. At maximal tibial tuberosity advancement, or maximal Ti-TT, mean CTS was negative $2.9 \pm 1.3 \mathrm{~mm}$, indicating a caudal subluxation. This was statistically different from both the normal intact CrCL stifles and the CrCL deficient stifles. When Ti-TT was reduced to the optimal distance, termed the critical point, mean CTS was $2.3 \pm 2.2 \mathrm{~mm}$ which was statistically different from the intact $\mathrm{CrCL}$ and the maximally advanced TTA group (Figure 2). The joint was considered clinically stable despite the difference between this group and the intact CrCL group.

The mean corrected PTA 1) at maximal advancement was $80.8 \pm 5.0^{\circ}, 2$ ) at critical point was $90.3 \pm 9.0^{\circ}$ and 3) with no advancement was $105.8 \pm 6.2^{\circ}$ (Figure 3). The three values were significantly different from each other. The mean corrected PTA for the maximal advancement was significantly different from the reference angle of the proposed $90^{\circ}$. However, the mean corrected PTA 
for the critical point was not significantly different from the reference angle supporting that the procedure, when done as designed, will stabilize a CrCL deficient stifle joint when the PTA is near $90^{\circ}$.

The results given here are supportive of the procedure's goal which is to achieve a stable joint relative to CTS at a PTA of $90^{\circ}$. This was performed at only one standing angle with respect to the stifle and at only one physiologic load. This means that only one single point in the stance phase of the gait has been examined and cannot be extrapolated to the rest of the gait.

Several other biomechanical studies have been performed. Both the Kipfer $^{27}$ and Miller ${ }^{28}$ groups used a similar stifle angle and load applied as the Apelt study ${ }^{26}$ These also used CTS as the indicator for CrTT generation and thus the prevention of CTS as the proof of efficacy of the TTA in the CrCL deficient stifle. In both studies, the basic premise that TTA prevents CTS in the CrCL deficient stifle was verified at $135^{\circ}$ stifle angle and $30 \%$ axial load applied. ${ }^{27,28}$ A different biomechanical evaluation reported the 3-D kinematics of the canine stifle after TTA. ${ }^{31}$ Using a similar model, it was demonstrated that TTA restores normal contact area, peak pressure and pressure distribution along the tibial plateau in a $\mathrm{CrCL}$ deficient stifle at $135^{\circ}$ stifle extension. ${ }^{31}$

Despite these validations, some assumptions remain, i.e., that there is a reduction in RPF and that the PTL (and femorotibial pressure) is decreased when performing a TTA. ${ }^{20}$ These assumptions were made suggesting that the TTA had few issues with patellar tendonosis and were free of lesions within the 
joint associated with increased contact pressures. Published clinical studies implied an absence of problems with the patellar tendon and the joint surfaces; ${ }^{32-}$ ${ }^{34}$ however, these claims have yet to be experimentally substantiated.

Finally, there has been a suggestion that the PTA is more accurately determined by the method of the common tangent $\left(\mathrm{PTA}^{\mathrm{CT}}\right)^{35,36}$ as opposed to the method using the tibial plateau angle $\left(\mathrm{PTA}^{\mathrm{TPA}}\right) .{ }^{33}$ The former method has been proposed to be clinically more accurate as it takes into account the anatomic relationship between the femoral condyles and tibial plateau, as opposed to a static relationship of the tibial plateau with the latter. ${ }^{20}$ However, this proposal has yet to be evaluated despite its current clinical use (2007 Veterinary Symposium - The Surgical Summit; Pre-Symposium Laboratories: TTA Laboratory; Chicago, IL).

We hypothesized that TTA would neutralize CrTT to zero point values and reduce mean RPF below baseline values under different loading conditions (increased stifle joint flexion angles and increased axial force). In addition, we hypothesized that mean PTL would be significantly reduced by TTA as compared to baseline values, mean PTA ${ }^{\mathrm{TPA}}$ would be similar to mean PTA ${ }^{\mathrm{CT}}$ within groups, and that mean $\mathrm{PTA}^{\mathrm{TPA}}$ and mean $\mathrm{PTA}^{\mathrm{CT}}$ would be similar among groups. Furthermore, we hypothesized that mean PTA ${ }^{\mathrm{TPA}}$ and mean PTA ${ }^{\mathrm{CT}}$ would be equivalent to $90^{\circ}$ in any group. Finally, we hypothesized that PTA ${ }^{\mathrm{CT}}$ would be systematically smaller and less variable than PTA ${ }^{\mathrm{TPA}}$ in all conditions. 
CHAPTER 2

\section{MATERIALS AND METHODS}

\section{Limb Preparation}

Thirty cadaveric canine pelvic limbs were harvested from adult male and female mixed breed dogs euthanized for reasons unrelated to this study. All dogs were of similar size and weighing $25-35 \mathrm{~kg}$. None of the specimens had orthopedic disease of the stifle joint, as determined by radiographic evaluation and direct observation. Limbs were freed of all soft tissues from the proximal aspect of the metatarsus to the proximal aspect of the femur, carefully preserving the stifle and talocrural joint capsules, the patellar tendon, and all collateral ligaments.

The proximal aspect of the femur was osteotomized just distal to the greater trochanter and the femoral diaphysis was fixed into a 12-cm long aluminum tube (McMaster-Carr Supply Company; Cleveland, $\mathrm{OH}$ ) of 3.3-cm in diameter using 4 3.5-mm cortical screws (Synthes Vet, Paoli, PA); 
additionally, the femurs were potted within these tubes with an acrylic (Bondo Body Filler, Bondo Corporation, Atlanta, GA). Radiopaque fiduciary markers (2.5-mm stainless-steel spheres; McMaster-Carr Supply Company; Cleveland, $\mathrm{OH}$ ), were placed at the distal aspect of the diaphysis of the femur and tibia, and mid-diaphysis of the $3^{\text {rd }}$ metatarsal bone as markers to determine stifle and talocrural joint angles.

A hole was drilled with a 2.5 - $\mathrm{mm}$ drill bit mediolaterally in the proximal third of the patella and a 1/16" braided steel cable was inserted and held in a 2$\mathrm{cm}$ loop with an oval crimp sleeve. This also was performed in the proximal one-third of the tuber calcis. A 2-cm craniomedial parapatellar stifle arthrotomy was performed and the infrapatellar fat pad was excised. The CrCL was identified and a loop of 22 gauge cerclage wire was loosely twisted to encircle its insertion. A midbody medial meniscal release was performed through a $1-\mathrm{cm}$ caudomedial arthrotomy. Two 3.5-mm cortical bone screws (Synthes, USA; Paoli, PA) were placed at the medial and lateral femorofabellar articulations. A $1-3 / 8$ " eye hook was inserted into the caudal tibia $1-\mathrm{cm}$ distal to the joint surface.

The TTA procedure was performed using the commercially available instrumentation (Kyon; Zurich, Switzerland). A drill guide was used to position the holes for a 5 tine fork $\left(\mathrm{Kyon}^{\circledR}\right.$; Zurich, Switzerland) on the cranial edge of the tibial crest. These were drilled with a $2.0 \mathrm{~mm}$ bit. An osteotomy of the tibial crest from the cranial margin of the medial meniscus to the junction of the tibial 
crest and tibial shaft was made using an oscillating saw (Stryker 2108 sagital saw; Kalamazoo, MI). The osteotomy was completed distally but only partial thickness proximally. The custom-made stainless-steel hinge plate, designed by Apelt $^{26}$, was secured to the crest fragment with $3.5 \mathrm{~mm}$ cortical bone screws (Synthes, USA; Paoli, PA) on the tibial shaft and the 5 fork tine (Kyon ${ }^{\circledR}$; Zurich, Switzerland) on the crest fragment. This hinge plate allowed the tibial tuberosity to be advanced in the frontal plane by advancing a set screw placed

through the tibial tuberosity that was oriented in the craniocaudal plane. ${ }^{26}$ Once the plate was secured, the osteotomy was completed proximally.

All specimens were wrapped in saline $(0.9 \% \mathrm{Na} C L)$ solution soaked towels and frozen at $-20^{\circ} \mathrm{C}$ until testing. Soft tissues were kept moist throughout the experiment with isotonic saline solution.

\section{Biomechanical Testing}

The 30 limbs were randomly divided into 3 groups. Group 1: 10 limbs tested at stifle and talocrural joint angles of $135 \pm 5^{\circ}$ and $145 \pm 5^{\circ}$, respectively, with $30 \%$ body weight axial load; Group 2: 10 limbs tested at stifle and talocrural angles of $145 \pm 5^{\circ}$ and $135 \pm 5^{\circ}$, respectively, again with $30 \%$ body weight axial load; and Group 3: 10 limbs tested at stifle and talocrural joint angles of $135 \pm 5^{\circ}$ and $145 \pm 5^{\circ}$, respectively, $50 \%$ body weight axial load.

Prior to testing, limbs were thawed at room temperature. The aluminum tube on the proximal femur was attached to the custom made limb press 
apparatus with a simulated coxofemoral joint angle of $70^{\circ} .{ }^{26}$ A small loop of 1/16" braided steel cable and an interposed 3/16" turnbuckle was used to attach the caudal femoral screws to the tuber calcis to simulate the gastrocnemius muscle. Similarly, a turnbuckle and spring was attached to the patellar cable loop. A cable was inserted through a hole centered in the patella and connected to the proximal femoral holding tube with a spring and turnbuckle to simulate the quadriceps mechanism; additionally, a load cell (MLP-300, Transducer Techniques Inc; Temecula, CA) was interposed between the cable connections. This load cell measured patellar tendon load (PTL). A flat load transducer (B201-low force series, Flexiforce; South Boston, MA) was then placed in the femoropatellar joint space. This load cell measured retropatellar force (RPF). The limb was then loaded in the limb press with an axial load of $30 \%$ body weight; the tibial tuberosity was maintained in the caudal most position such that contact was present along the osteotomy surfaces. The stifle and tarsal joint angles were set to the appropriate position (depending on the group tested) by adjusting the turnbuckles and foot placement. A turnbuckle was then attached from the eye hook placed in the caudal aspect of the proximal tibia and secured caudally perpendicular to the vertical axis of the limb, again with an interposed load cell. This load cell measured cranial tibial thrust force (CrTT) (Figure 1). Once all connections were secured and the limb stabilized in the desired position of angulation, the RPF load cell reading was recorded and the PTL and CrTT load cells were zeroed. 
A lateral radiographic projection (HF-100, MinXRay Unit; Northbrook, IL) of the loaded limb was obtained. The appropriate stifle and talocrural joint angles were confirmed as was the positioning of the retropatellar load transducer. The CrCL was transected under load at its origin with a \#11 blade through a minimal caudal arthrotomy just lateral to the caudal cruciate ligament insertion. A medial midbody meniscal release was performed through the same incision. Complete transection of the CrCL was confirmed by removal of the intact looped cerclage wire from the craniomedial arthrotomy. Readings from all the load cells were recorded, which were defined as the baseline values. The craniocaudal machine screw in the custom TTA hinge plate was tightened in one-revolution increments (thread pitch $=1.06 \mathrm{~mm}$ ), thus advancing the tibial tuberosity; readings from the three load cells were recorded after each revolution. The screw was advanced until CrTT showed a value $\leq$ zero (neutral point of advancement - NPA); if < zero, this was the closest reading to zero based upon a full revolution of the set screw. A lateral projection radiograph again was obtained. If at any time the limb position shifted, the stifle joint subluxated or any problems with the fixation were observed (e.g., screw stripping, implant failure), the specimen was discarded.

After test completion, all limbs were removed from the testing apparatus and the stifle joint was re-evaluated via a gross visual examination. Complete transection of the $\mathrm{CrCL}$ and complete meniscal release were verified. 
Analysis

All radiographs were developed, scanned and digitized (Lumiscan, part \# 0068-210, Lumissys Inc; Sunnyvale, CA). Radiographic analysis consisted of confirming joint angles, measuring tibial plateau angle (TPA) and determining PTA by the tibial plateau method $\left(\mathrm{PTA}^{\mathrm{TPA}}\right)$ and the common tangent method $\left(\mathrm{PTA}^{\mathrm{CT}}\right),{ }^{35,36}$ (Figure 4). These angles were determined from the original radiographs by one observer (RJB). These radiographs also were used to determine spring length change by measuring the change in position of the insertion of the cable at the patella by direct overlay. The distance was then multiplied by the spring constant $(12.1 \mathrm{~N} / \mathrm{mm})$ which was subtracted from PTL to account for the effect of spring stretching induced tension.

\section{Statistics}

Descriptive statistics were used to summarize the mean body weight and mean TPA of the dogs. Descriptive statistics were also used to report values for CrTT, since by design the test was concluded when the CrTT force returned to baseline values. The RPF at the NPA was compared to baseline values using a two-tailed sign test with the probability of success set at 0.5 (50\% chance the values either increase or decrease) and significance set at a p-value of 0.05 . For this comparison mean difference and two-tailed p-value were reported. Pairwise comparisons of mean PTL at baseline and NPA were performed with a paired t-test. Pair-wise comparisons of PTA ${ }^{\mathrm{TPA}}$ and $\mathrm{PTA}^{\mathrm{CT}}$ within groups were 
performed utilizing a paired t-test. Comparisons between groups were made with a one-way ANOVA and when significant differences were detected, pairwise comparisons were made with a Tukey's post hoc test. Significance was set at a p-value of 0.05 .

Equivalence tests were used to test each method's $\left(\mathrm{PTA}^{\mathrm{TPA}}\right.$ and PTA $\left.{ }^{\mathrm{CT}}\right)$ mean for equivalence to $90^{\circ}$ by determining the narrowest "zone of indifference" (e.g., $90^{\circ}+/-2^{\circ}$ ) for which the means outside the range could be considered statistically different from $90^{\circ}$. A wider zone indicates the mean is farther from $90^{\circ}$ than a narrow zone. Equivalence tests also were used to compare the measurement techniques' mean angles by determining the narrowest "zone of indifference" for which the means could be considered statistically different. A wider zone suggests the means are less equivalent (i.e., farther apart) than a narrower zone.

Bartlett's test was used to determine if the variances between PTA ${ }^{\text {TPA }}$ and $\mathrm{PTA}^{\mathrm{CT}}$ were equal. A p-value $<0.05$ was considered significant. 


\section{CHAPTER 3}

\section{RESULTS}

During testing, one sample in Group 2 demonstrated tibial subluxation and thus was excluded from analysis. Likewise, one sample in Group 1 had a shift in the stifle joint angle, and 4 samples in Groups 1 and 3 had advancement screw failure; these also were excluded from the analysis.

The mean body weight of the dogs was $27.4 \mathrm{~kg}$ (range $23-35 \mathrm{~kg}$ ). The mean TPA was $25.8^{\circ}$. CrTT returned to zero point values in all specimens (Figures 5 \& 6). Mean RPF at NPA was reduced below baseline values in all groups (Figures $5 \& 6$ ). In Group 1 the mean difference was $-3.32 \mathrm{~N}$ and the two-tailed p-value was 0.0078 . In Group 2 the mean difference was $-1.13 \mathrm{~N}$ and the two-tailed p-value was 0.0078. In Group 3 the mean difference was $-2.63 \mathrm{~N}$ and the two-tailed p-value was 0.031. Mean PTL at NPA was reduced below baseline values in all groups (Figures $5 \& 6$ ). In Group 1 the mean baseline PTL was $1.41 \mathrm{~N}$ and the mean NPA PTL was $-17.2 \mathrm{~N}(\mathrm{p}=0.0011)$. In Group 2 the mean baseline PTL was $2.07 \mathrm{~N}$ and the mean NPA PTL was $-18.7 \mathrm{~N}(\mathrm{p}=$ 
0.0010). In Group 3 the mean baseline PTL was $4.57 \mathrm{~N}$ and the mean NPA PTL was $-6.68 \mathrm{~N}(\mathrm{p}=0.022)$.

The PTA at the NPA using PTA ${ }^{\mathrm{TPA}}$ was greater than the PTA at the NPA using $\mathrm{PTA}^{\mathrm{CT}}$ in group 1 (mean $\left.\mathrm{PTA}^{\mathrm{TPA}}=91.1^{\circ}, \mathrm{PTA}^{\mathrm{CT}}=88.4^{\circ}, \mathrm{p}=0.009\right)$ and group $2\left(\right.$ mean $\mathrm{PTA}^{\mathrm{TPA}}=98.2^{\circ}, \mathrm{PTA}^{\mathrm{CT}}=91.1^{\circ}, \mathrm{p}=0.006$ ). There was not enough evidence to suggest that $\mathrm{PTA}^{\mathrm{TPA}}$ differed from $\mathrm{PTA}^{\mathrm{CT}}$ in group 3 (mean $\left.\mathrm{PTA}^{\mathrm{TPA}}=84.0^{\circ}, \mathrm{PTA}^{\mathrm{CT}}=86.3^{\circ}, \mathrm{p}=0.23\right) . \mathrm{PTA}^{\mathrm{TPA}}$ was significantly different among groups $(\mathrm{p}=0.0005)$. Group $2\left(\right.$ mean $\left.\mathrm{PTA}^{\mathrm{TPA}}=98.3^{\circ}\right)$ was greater than both Groups $1\left(\right.$ mean $\left.\mathrm{PTA}^{\mathrm{TPA}}=91.1^{\circ}\right)$ and $3\left(\right.$ mean $\left.\mathrm{PTA}^{\mathrm{TPA}}=84.0^{\circ}\right)$ in post hoc analysis. PTA ${ }^{\mathrm{CT}}$ also varied significantly among groups $(\mathrm{p}=0.032)$. In contrast, only group $2\left(\mathrm{PTA}^{\mathrm{CT}}=91.1^{\circ}\right)$ was greater than group $3\left(\mathrm{PTA}^{\mathrm{CT}}=86.3^{\circ}\right)$.

The threshold at which the PTA ${ }^{\mathrm{TPA}}$ could be considered significantly different from $90^{\circ}$ for Group 1 was $3.7^{\circ}(\mathrm{p}=0.045)$, for Group 2 it was $12.4^{\circ}(\mathrm{p}$ $=0.048)$, and for Group 3 it was $9.5^{\circ}(\mathrm{p}=0.045)$. The threshold at which the $\mathrm{PTA}^{\mathrm{CT}}$ could be considered significantly different from $90^{\circ}$ for Group 1 was $4.0^{\circ}$ $(\mathrm{p}=0.044)$, for Group 2 it was $2.6^{\circ}(\mathrm{p}=0.049)$, and for Group 3 it was $5.4^{\circ}(\mathrm{p}=$ 0.045). Overall (all groups combined), the threshold at which PTA ${ }^{\mathrm{TPA}}$ could be considered significantly different from $90^{\circ}$ was $4.6^{\circ}(\mathrm{p}=0.046)$ and for $\mathrm{PTA}^{\mathrm{CT}}$ it was $2.9^{\circ}(\mathrm{p}=0.041)$.

Based upon the results of the equivalence testing, the $\mathrm{PTA}^{\mathrm{CT}}$ was numerically smaller in Groups 1 and 2, and numerically larger in Group 3. In Group 1, the threshold at which the PTA ${ }^{\mathrm{TPA}}$ could be considered significantly 
different from the $\mathrm{PTA}^{\mathrm{CT}}$ was $6.5^{\circ}(\mathrm{p}=0.045$; Figure 7). In Group 2 the threshold at which the PTA ${ }^{\text {TPA }}$ could be considered significantly different from the $\mathrm{PTA}^{\mathrm{CT}}$ was $11.7^{\circ}(\mathrm{p}=0.048$; Figure 7$)$. In Group 3 the threshold at which the PTA ${ }^{\text {TPA }}$ could be considered significantly different from the PTA ${ }^{\mathrm{CT}}$ was $6.6^{\circ}$ $(p=0.047$; Figure 7). Overall (all groups combined), the threshold at which the $\mathrm{PTA}^{\mathrm{TPA}}$ could be considered significantly different from the $\mathrm{PTA}^{\mathrm{CT}}$ was $6.1^{\circ}(\mathrm{p}$ $=0.047$; Figure 8).

Bartlett's test revealed a significant difference in the variances of $\mathrm{PTA}^{\mathrm{TPA}}$ and $\mathrm{PTA}^{\mathrm{CT}}(\mathrm{p}=0.0007$; Figure 9). 


\section{CHAPTER 4}

\section{DISCUSSION}

The selected stifle joint angles were based upon a published kinematic analysis of the dog's gait, where the stance phase begins at $\sim 145^{\circ}$ and progressively flexes to $\sim 135^{\circ}$ through $80 \%$ of the stance phase. ${ }^{37}$ Similarly, CrCL peak forces in a quasi-static 3-D mathematical model of the canine stifle joint are reported to occur at $\sim 40 \%$ into the stance phase, which again is at $\sim 135^{\circ}$ of stifle joint extension, ${ }^{38}$ and is further supported by an in vivo study in a quadruped model using goats. ${ }^{39}$

A mid-body medial meniscal release was performed to prevent any additional contribution to stabilizing the joint, as the medial meniscus is a secondary stabilizer against $\mathrm{CrTT}^{40}{ }^{40}$ Elimination of the meniscal contribution to stability was thought to be an important component of accurately evaluating CrTT in this model. 
This ex vivo model demonstrated a direct increase of CrTT upon transection of the CrCL under load. Therefore, the model verified that the intact CrCL was responsible for neutralization of CrTT. Advancement of the tibial tuberosity, in all cases, showed a nearly linear decrease in the magnitude of the CrTT as the tuberosity was advanced; furthermore, sufficient advancement was obtained to neutralize CrTT (NPA). It also was evident in some cases that a reading of $<0$ could be obtained with additional tibial tuberosity advancement, which is consistent with a shift in direction of the tibiofemoral shear forces, as caudal tibial thrust could be demonstrated. The CrTT was significantly reduced in all cases and neutralized in all legs. The discrepancy among NPA CrTT values was a result of the method of incremental advancement where set screw advancement always was a full revolution, which resulted in a slight negative value in some cases at the defined NPA.

Retropatellar force also decreased with tibial tuberosity advancement, again in a nearly linear manner. However, there was a large amount of variation in each individual leg with each subsequent turn of the set screw and with regard to the amount of overall reduction observed. This variation could have accounted for the inconsistency observed with the NPA RPF, and also the magnitude of change observed over time. The shape of the pressure sensor to record RPF was flat, and despite its small size, did not conform well to the shape of the trochlear sulcus. Furthermore, inserting this sensor into the appropriate position through a small incision into the joint was difficult, and the final resting 
position may have been less than ideal. Lastly, because of the orientation of this model, with a constraint on the distal end of the tibial tuberosity, there was a slight distal shift of the patella in relationship to maintaining its normal position with tuberosity advancement (Figure 10); this shift also could have played a role in the sensor not being ideally situated. Note that in the clinical situation, the entire tibial crest is allowed to shift a few mm proximally to ensure that patella position remains unaltered (i.e., the arc of rotation of the patellar tendon's attachment to the tibial tuberosity remains centered at the patella). ${ }^{33}$ Therefore, the mismatch between the patella and corresponding femoral sulcus probably is to blame for the inconsistencies observed. All these factors may also account for the lack of reduction in RPF seen immediately after CrCL transection as predicted by a canine 3-D mathematical stifle joint model ${ }^{38}$ alternatively, the predictions with the mathematical model may not be accurate.

Patellar tendon load also was shown to decrease in a nearly linear fashion with tibial tuberosity advancement; however, it was necessary to adjust the raw values recorded due to the spring tension effect, as in this model the position of the patella moved distally with tuberosity advancement because of the hinge restraint as was noted previously. In the clinical situation, the center of rotation of the tibial tuberosity is maintained at the level of the patella, ${ }^{33}$ and not the distal end of the tibial tuberosity as it is constrained in this model. The latter causes a distal shift of the patella with tuberosity advancement, thus artificially increasing the PTL values as the spring used to simulate the 
quadriceps mechanism lengthens. The difference in length of the spring from baseline to NPA was measured and the spring tension, which is linear, calculated [(difference in length) X (spring constant)]. After subtracting the spring tension, the true measure of PTL was determined at the NPA. The actual PTL significantly decreased with advancement in all groups.

These findings with CrTT, RPF and PTL all are in agreement with other experimental $^{26-28,31}$ and mathematical ${ }^{18,23}$ models. This model clearly demonstrates that advancing the tibial tuberosity decreases CrTT, RPF and PTL, supporting the hypotheses. This study further supports the claim that the reduction of CrTT and thus stabilization of the CrCL deficient stifle joint after TTA is achieved through an alteration of PTA.

In this model, $\mathrm{PTA}^{\mathrm{TPA}}$ was significantly greater than $\mathrm{PTA}^{\mathrm{CT}}$ at an applied load of $30 \%$ body weight at both stifle joint angles evaluated $\left(135^{\circ}\right.$ and $\left.145^{\circ}\right)$, but was not shown to be different at the higher load (50\% body weight). The PTA did, however, vary between the groups with either method, but appeared to have less of a difference when using PTA ${ }^{\mathrm{CT}}$.

An equivalence test was performed to test whether the two methods were equal, thus any differences found would be of no practical consequence. Since there always will be some difference between alternate methods, we attempted to determine if the differences could be considered clinically relevant. Therefore, we set the hypothetical equivalence value for comparison of either $\mathrm{PTA}^{\mathrm{TPA}}$ or $\mathrm{PTA}^{\mathrm{CT}}$ to $90^{\circ}$. The threshold for each of the groups evaluated, at 
which the PTA could be significantly different from $90^{\circ}$, was larger for PTA ${ }^{\mathrm{TPA}}$ than PTA $^{\mathrm{CT}}$ in all groups.

The PTA ${ }^{\text {TPA }}$ varied more than PTA $^{\mathrm{CT}}$ in all groups, and also appeared to vary more with stifle joint flexion angle. This can be expected, since PTA ${ }^{\mathrm{CT}}$ accounts for variations in femoral condyle anatomy, and also is a dynamic measure that accounts for alteration in the femorotibial contact point, while the $\mathrm{PTA}^{\mathrm{TPA}}$ is a static measure independent of the femur. ${ }^{35}$ The $\mathrm{PTA}^{\mathrm{CT}}$ may be more accurate at reflecting the true PTA due to the craniocaudal translation of the femoral condyles and the contact point with the tibia during flexion/extension. ${ }^{35}$ The PTA ${ }^{\mathrm{CT}}$ method appears to be less influenced by alterations in stifle joint flexion angle, thus it can be preferentially recommended (over $\mathrm{PTA}^{\mathrm{TPA}}$ ) for clinical use in preoperative planning of the TTA procedure.

The PTA required to neutralize CrTT at an applied load of 50\% body weight (group 2) was less than $90^{\circ}$ utilizing both measurement methods. This was likely due to creation of a larger tibiofemoral shear force at higher loads that required greater amount of tibial tuberosity advancement to achieve NPA, and thus a final lower PTA was required for neutralization of CrTT to occur. Target PTA values of $<90^{\circ}$ may be required to achieve definitive neutralization of CrTT, and may need to be considered in dogs functioning under higher limb loads; however, muscular co-contraction was not considered in this model, which may counter this supposition. 


\section{CHAPTER 5}

\section{CONCLUSION}

Our data further support the proposed mechanism of action for TTA in reducing CrTT, and in addition support the propositions of reduced RPF and PTL; however, there are a number of limitations when considering such an $e x$ vivo evaluation of the clinical situation. The current model is an improvement

compared to previous ex vivo models ${ }^{26-28}$ as the limb is restrained such that stability is maintained under a variety of loading conditions, thus allowing any combination of loads or joint angles. This restraint also provides a means to instrument the limb such that direct measures of forces can be obtained; additionally, the $\mathrm{CrCL}$ is transected under a load in situ such that immediate measures can be obtained comparing the intact and deficient CrCL and also after TTA. Despite these improvements, this model remains a gross simplification of a very complex joint. Furthermore, only a single additional stifle joint angle and load were evaluated in this study, which equate to finite points in a 2-D model. 
CHAPTER 6

APPENDICES 
APPENDIX A

\section{FIGURE 1. LIMB PRESS APPARATUS}

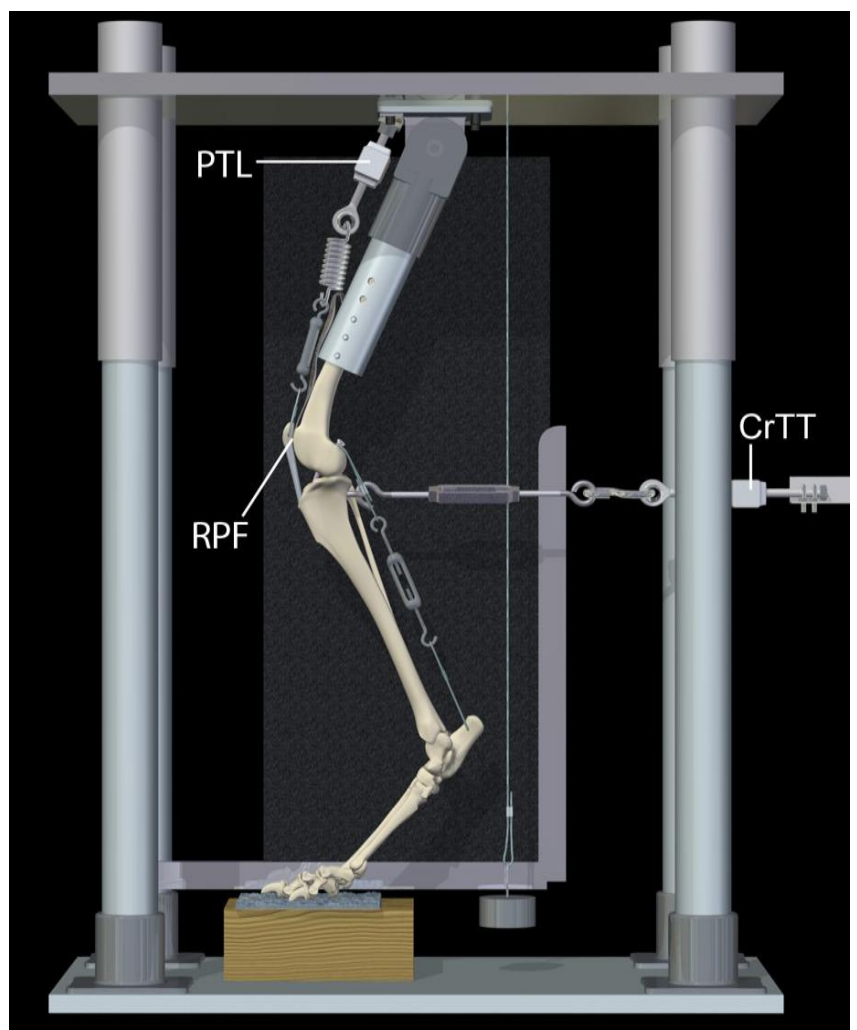

Illustration of the custom limb press apparatus. Note the interposition of the load cells on the caudal proximal tibia (cranial tibial thrust - CrTT), along the simulated quadriceps mechanism (patellar tendon load - PTL) and the pressure sensor underneath the patella (retropatellar force - RPF). 
APPENDIX B

FIGURE 2. CRANIAL TIBIAL SUBLUXATION GRAPH FROM APELT, 2007

\section{Cranial Tibial Subluxation (CTS)}

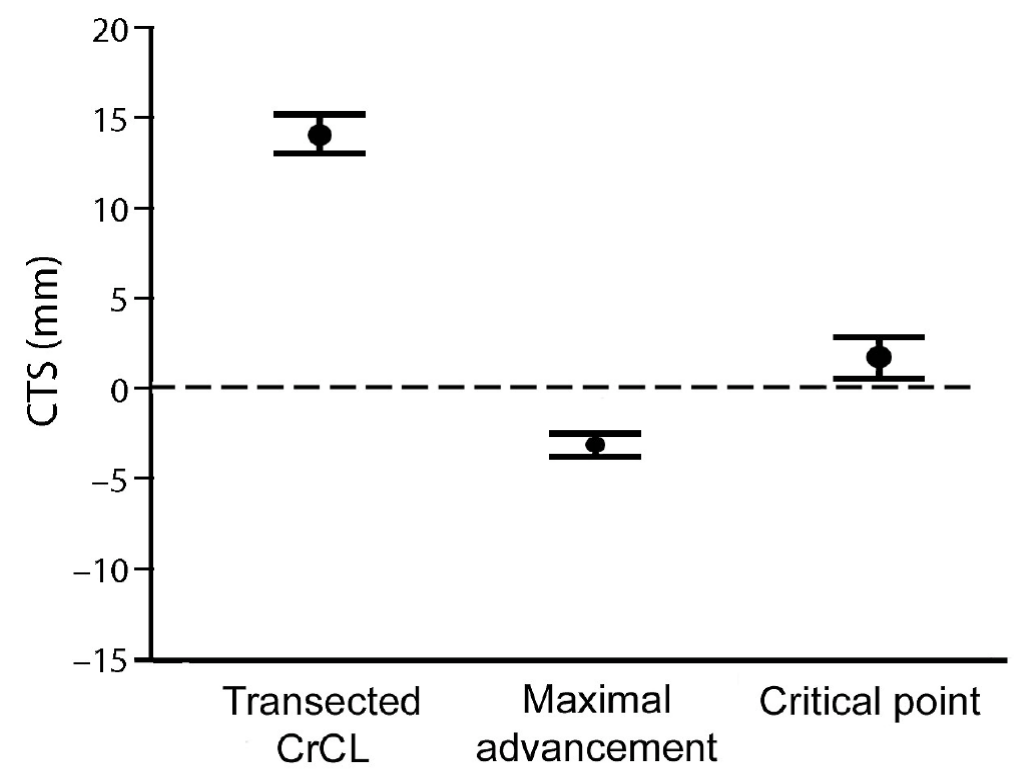

Graph representing the amount of measured cranial tibial subluxation (CTS) for canine CrCL deficient stifles without and with $\mathrm{TTA}_{\mathrm{C}}$ and $\mathrm{TTA}_{\mathrm{M}}{ }^{26}$. The critical point advancement demonstrates a CTS not different from zero indicating a stable stifle joint. 
APPENDIX C

FIGURE 3. PATELLAR TENDON ANGLE GRAPH FROM APELT, 2007

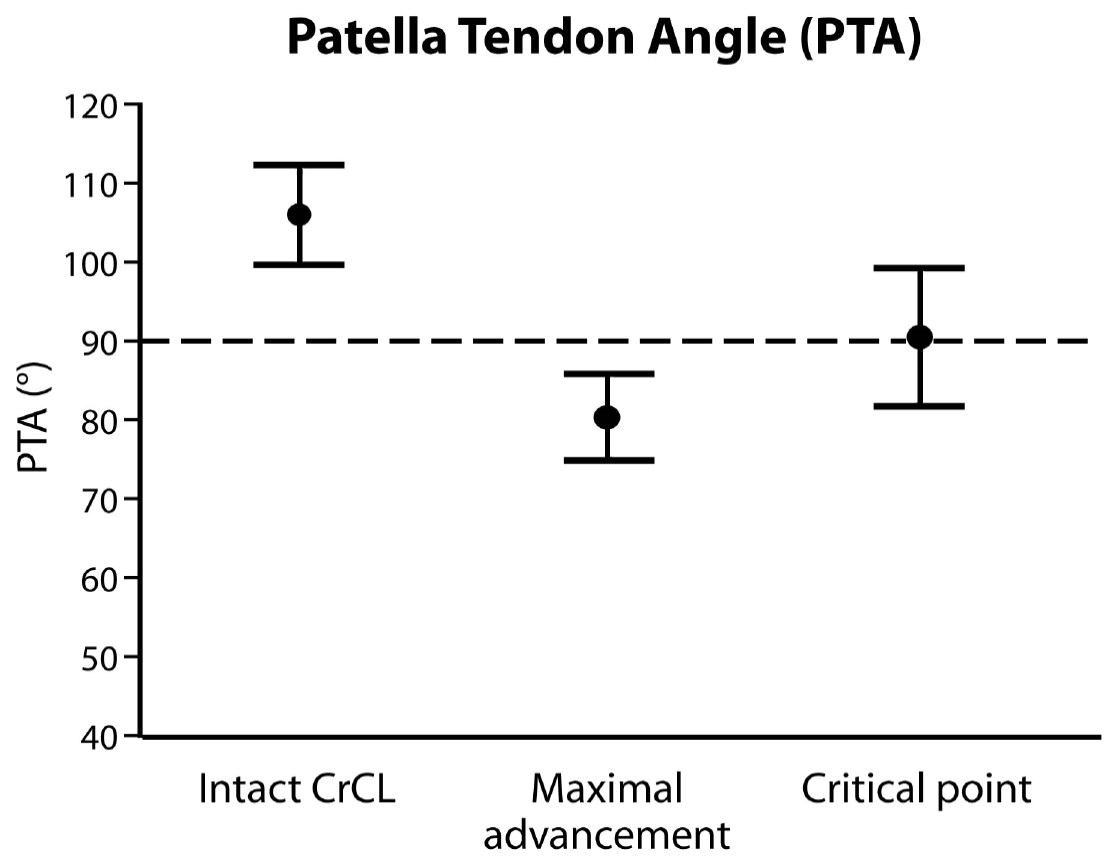

Graph representing the patellar tendon angle (PTA) for canine CrCL deficient stifles without and with $\mathrm{TTA}_{C}$ and $\mathrm{TTA}_{\mathrm{M}}$ (Apelt. 2006). The critical point advancement is not significantly different from the goal of PTA $=90^{\circ}$. 


\section{APPENDIX D}

FIGURE 4. PATELLAR TENDON ANGLE MEASUREMENT METHODS

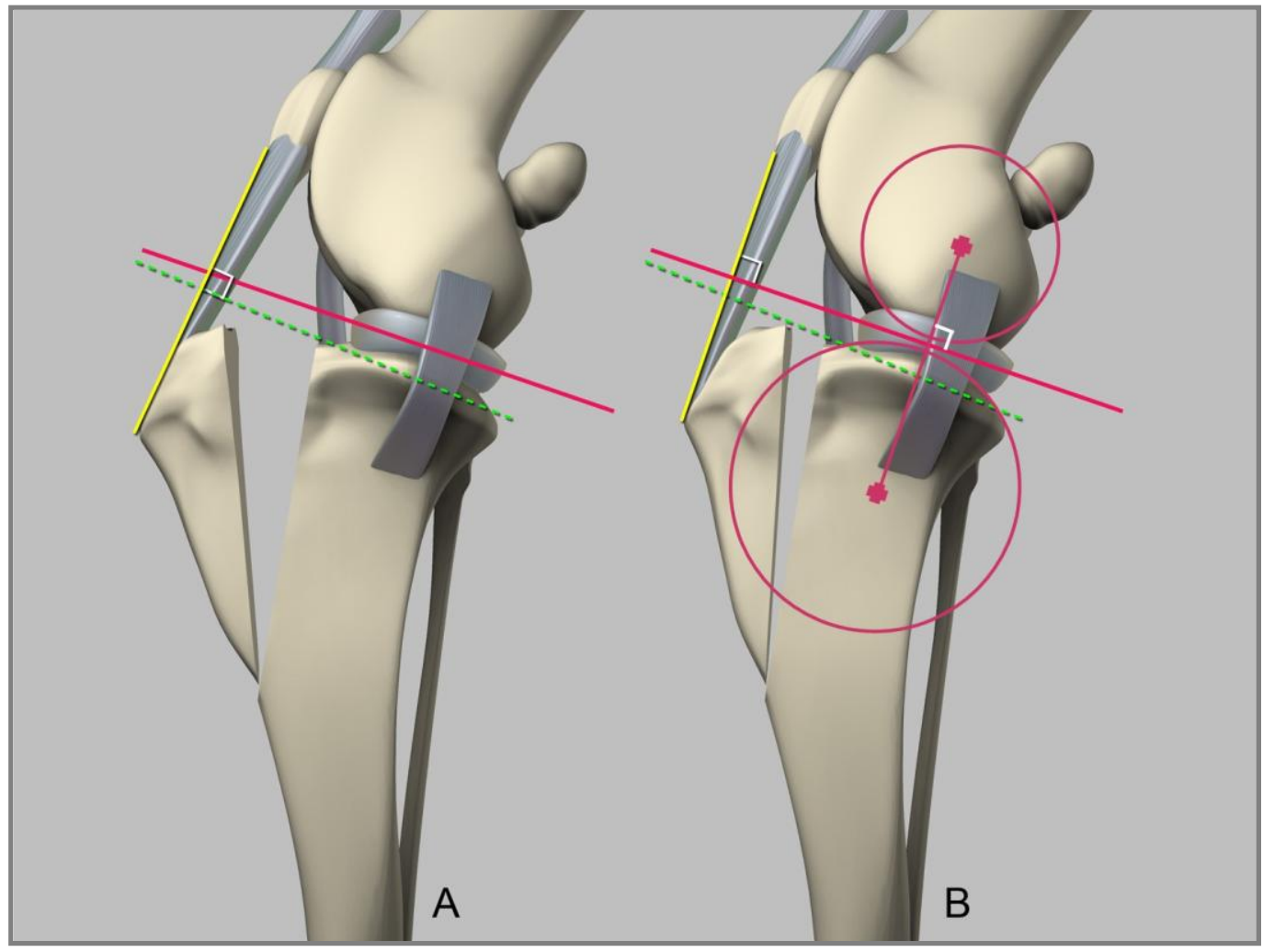

Illustration demonstrating the two methods of measuring patellar tendon angle (PTA) so as to obtain the planned $90^{\circ}$ PTA after tibial tuberosity advancement. A) PTA measurement using tibial plateau angle $\left(\mathrm{PTA}^{\mathrm{TPA}}\right)$; dotted line is drawn along the tibial plateau slope that intersects with the patellar tendon. B) PTA 
measurement using common tangent method $\left(\mathrm{PTA}^{\mathrm{CT}}\right)$; solid line is drawn tangent to the femorotibial joint contact point that intersects with the patellar tendon (note that the dotted line is the tibial plateau axis). 


\section{APPENDIX E}

FIGURE 5. LINE GRAPHS OF GROUP 1 MEANS FOR CRANIAL TIBIAL THRUST, RETROPATELLARR FORCE AND PATELLAR TENDON LOAD
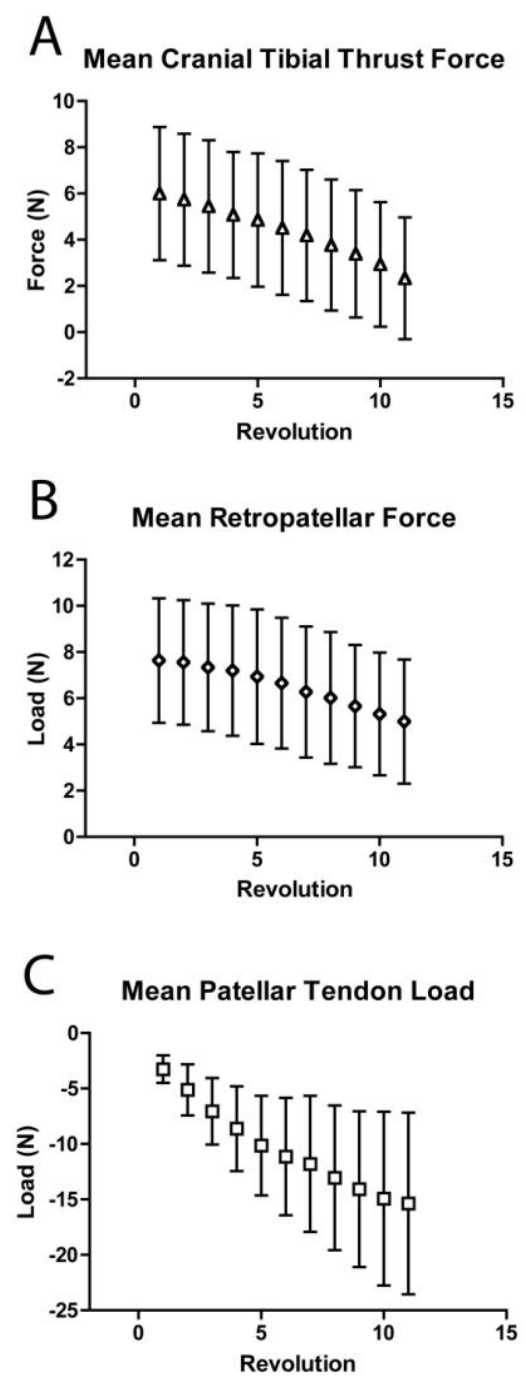
Line graphs of A) mean cranial tibial thrust (CrTT), B) mean retropatellar force (RPF) and patellar tendon load (PTL) +/- standard deviation as a function of force vs. revolutions in all specimens in group 1. A nearly linear relationship of decreasing force is observed in all three parameters. Note that these graphs illustrate data only to revolution 11 , the point at which all samples are represented. 
APPENDIX F

FIGURE 6. LINE GRAPHS OF SPECIMEN 2 FOR CRANIAL TIBIAL

THRUST, RETROPATELLARR FORCE AND PATELLAR TENDON LOAD

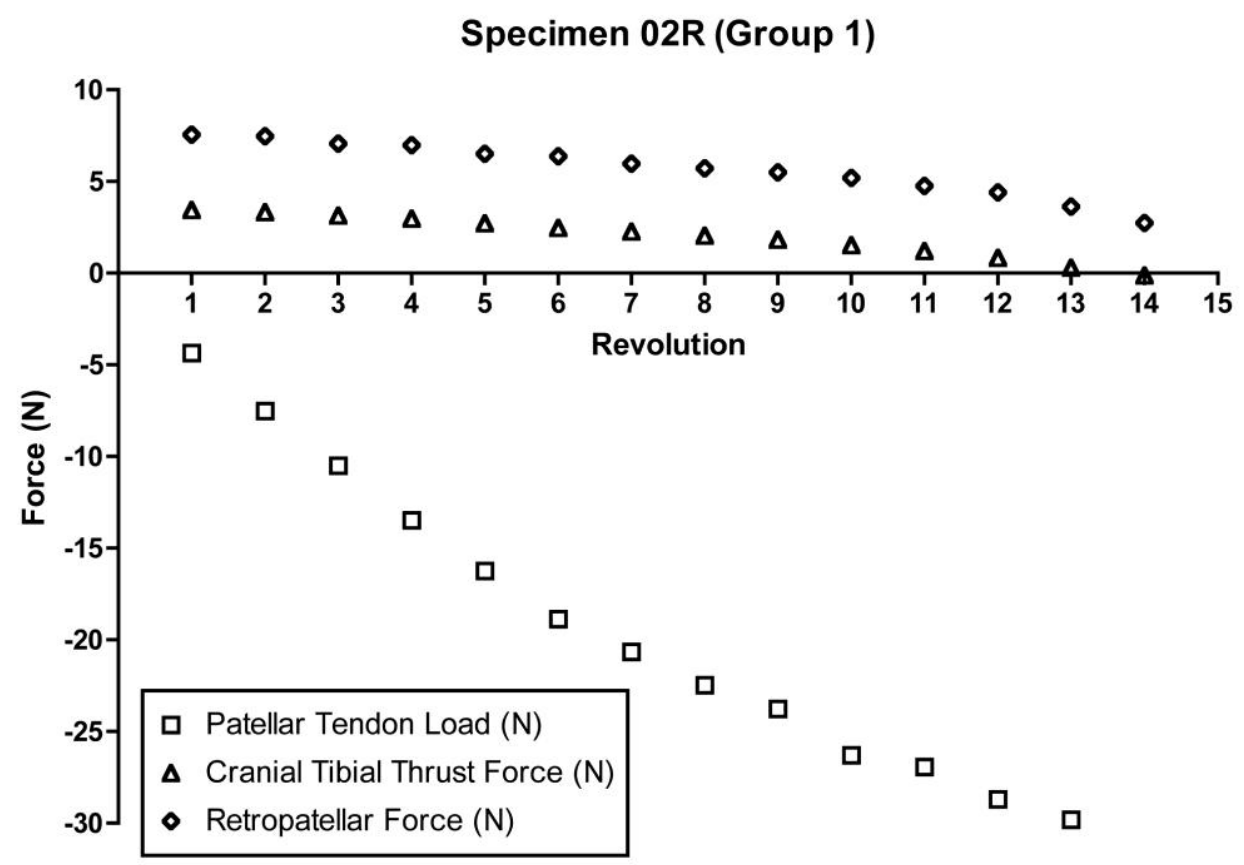

Line graph of CrTT, RPF and PTL as a function of force vs. revolutions of a single specimen in Group 1. A nearly linear relationship is observed: CrTT, RPF and PTL all decrease as the tibial tuberosity is advanced. 


\section{APPENDIX G}

\section{FIGURE 7. PRACTICAL EQUIVALENCE BY GROUP FOR PATELLAR}

\section{TENDON ANGLE}

\section{Practical Equivalence between PTA $^{\text {CT }}$ and PTA ${ }^{\text {TPA }}$}

Group 1

Specified Practical Difference Threshold Actual Difference in Means

$6.5^{\circ}$

Std Error of Difference

$$
\begin{array}{r}
-2.75^{\circ} \\
2.064799^{\circ}
\end{array}
$$

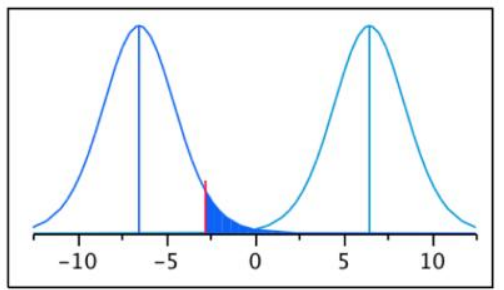

\begin{tabular}{|lrr|}
\hline & & \\
Test & t Ratio & p-Value \\
Upper Threshold & -4.47986 & 0.0003 \\
Lower Threshold & 1.816158 & 0.0454 \\
Max over both & & 0.0454 \\
\hline
\end{tabular}

Group 2

Specified Practical Difference Threshold

Actual Difference in Means

Std Error of Difference

$-7.125^{\circ}$ $2.564786^{\circ}$

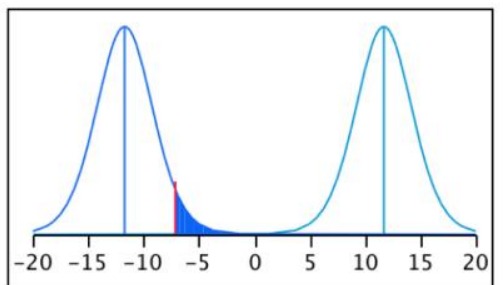

$\begin{array}{lrr}\text { Test } & \text { t Ratio } & \text { p-Value } \\ \text { Upper Threshold } & -7.33979 & <.0001 \\ \text { Lower Threshold } & 1.783775 & 0.0481 \\ \text { Max over both } & & 0.0481\end{array}$

Group 3

Specified Practical Difference Threshold Actual Difference in Means

Std Error of Difference

$2.333333^{\circ}$

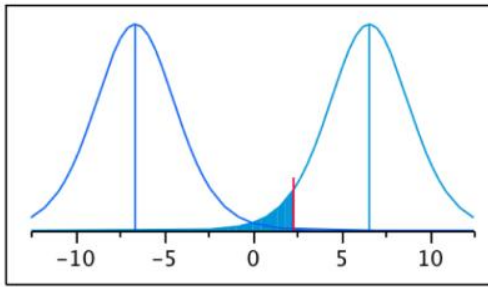

Test

Upper Threshold

Lower Threshold

Max over both 
Practical equivalence between patellar tendon angles as determined by either the common tangent or tibial plateau angle methods $\left(\mathrm{PTA}^{\mathrm{CT}}\right.$ vs. PTA ${ }^{\mathrm{TPA}}$ ). Groups 1, 2 and 3: thresholds at which the PTA ${ }^{\text {TPA }}$ could be considered significantly different from the $\mathrm{PTA}^{\mathrm{CT}}$ was $6.5^{\circ}, 11.7^{\circ}$ and $6.6^{\circ}$, respectively (the shaded area on each graph represents the actual difference of the means, PTA ${ }^{\mathrm{CT}}$ vs. PTA $^{\mathrm{TPA}}$ ). 


\section{APPENDIX H}

FIGURE 8. PRACTICAL EQUIVALENCE OF ALL SAMPLES FOR

\section{PATELLAR TENDON ANGLE}

All Groups Combined

Specified Practical Difference Threshold

Actual Difference in Means

Std Error of Difference

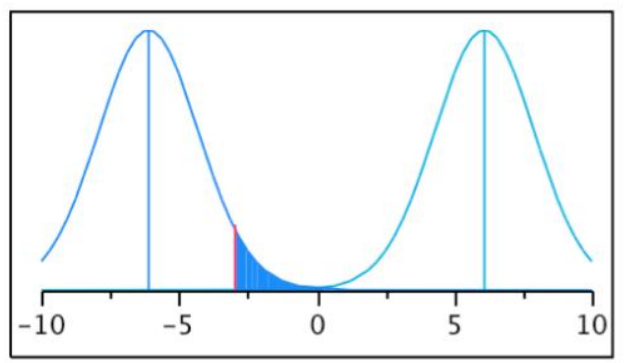

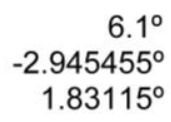

Test

Upper Threshold

Lower Threshold

Max over both

\section{t ratio}

$-4.94473$

1.717748

p-Value

$<.0001$

0.0466

0.0466

Practical equivalence for all groups between patellar tendon angles as determined by either the common tangent or tibial plateau angle methods $\left(\mathrm{PTA}^{\mathrm{CT}}\right.$ vs. PTA $\left.{ }^{\mathrm{TPA}}\right)$. The threshold at which the PTA ${ }^{\mathrm{TPA}}$ could be considered significantly different from the $\mathrm{PTA}^{\mathrm{CT}}$ was $6.1^{\circ}$. 


\section{APPENDIX I}

FIGURE 9. GRAPHICAL DEPICTION OF VARIANCES FOR PATELLAR TENDON ANGLE

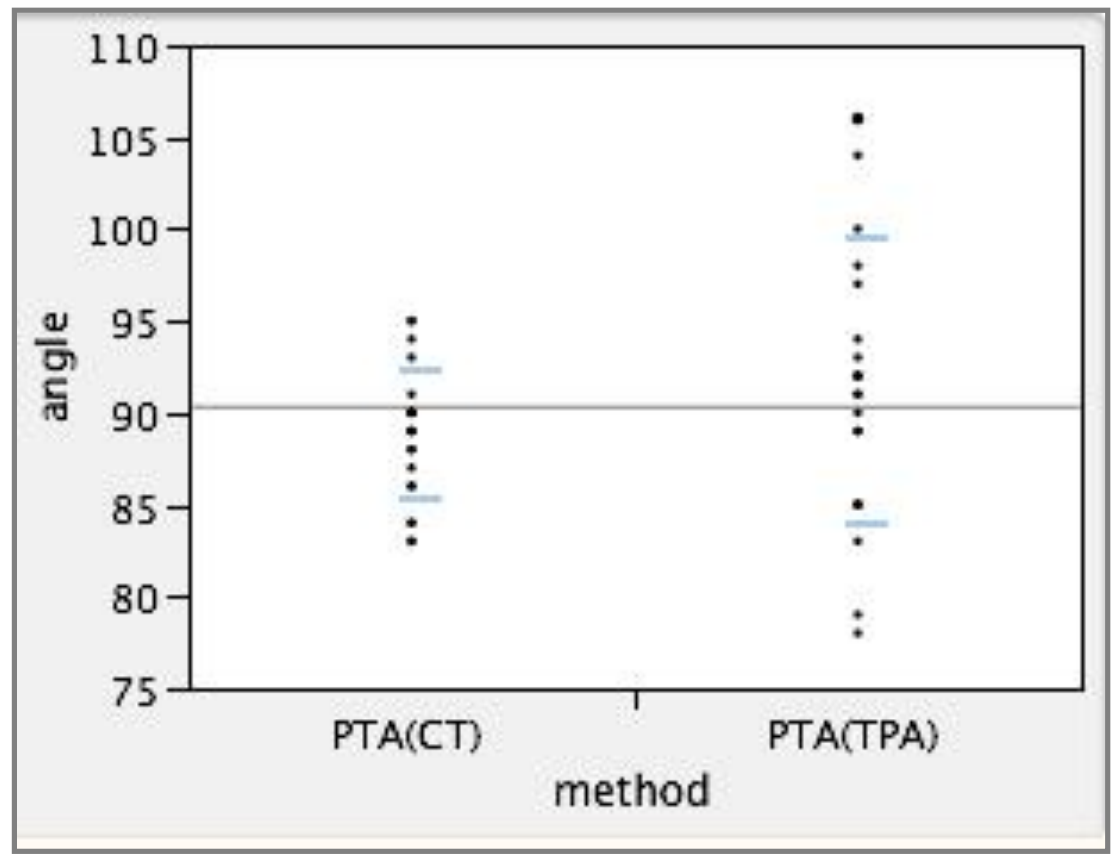

Graphical depiction of the variances of $\mathrm{PTA}^{\mathrm{TPA}}$ and $\mathrm{PTA}^{\mathrm{CT}}$. The $\mathrm{PTA}^{\mathrm{CT}}$ was significantly less variable than the PTA ${ }^{\mathrm{TPA}}$. Note that the horizontal bars depict the standard deviation of the mean with each method, and that the hypothetical equivalence value is set at $90^{\circ}$ 


\section{APPENDIX J}

FIGURE 10. SPRING TENSION EFFECT

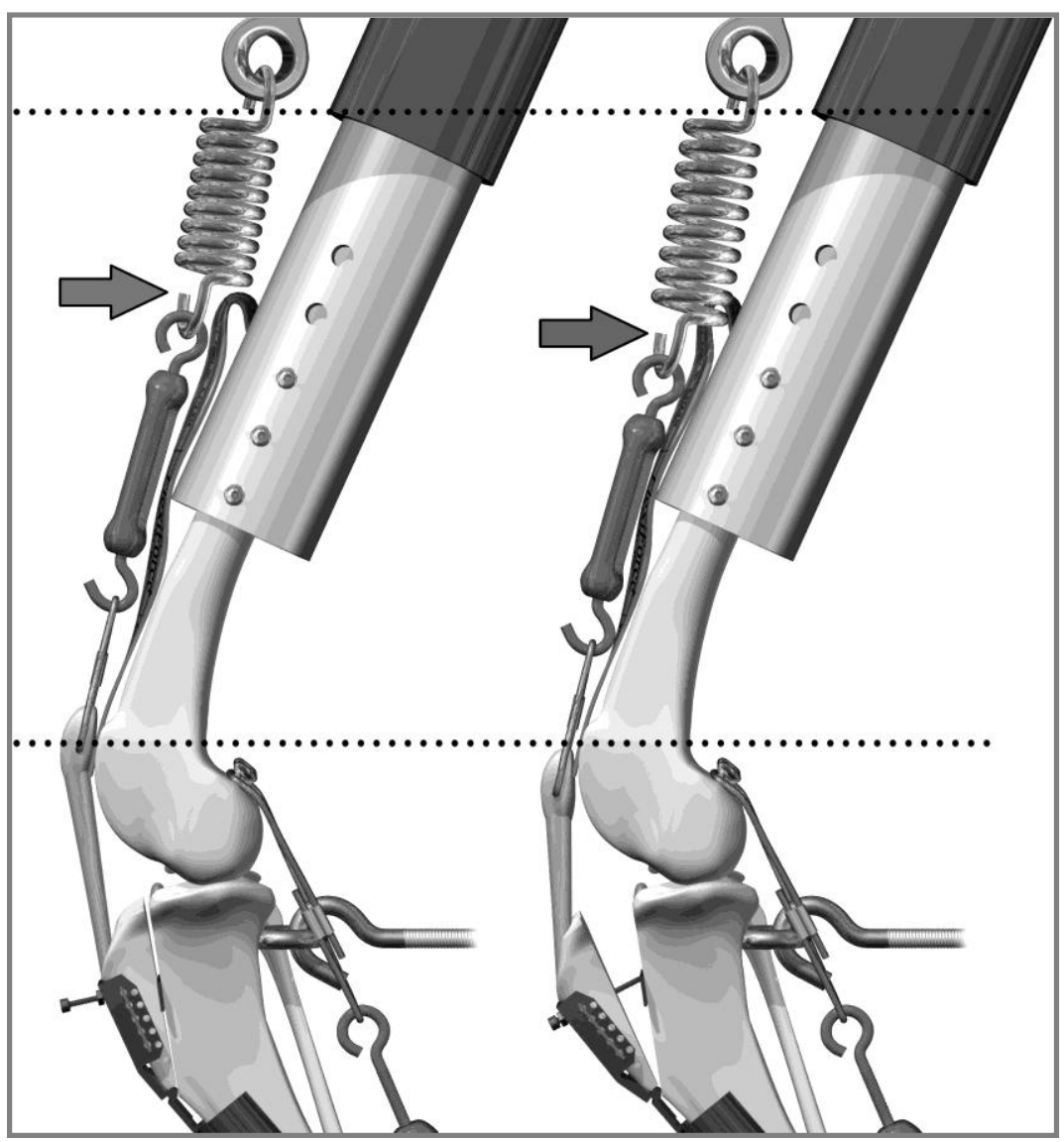

Illustration of the spring tension effect. Note that the tibial crest and tibial tuberosity do not shift proximally as the tuberosity is advanced (restrained distally by the custom hinge plate). The result is a shift of the patella position 
distally (lower dotted line); the proximal position of the spring remains unchanged (upper dotted line). The spring length increases due to the more distal positioning of the patella (arrows). The increased length of the spring (spring tension effect) must be accounted for when calculating the patellar tendon load (PTL). 


\section{WORKS CTIED}

1. Moore, KW, Read RA. Rupture of the cranial cruciate ligament in dogs - Part II. Diagnosis and management. Compend Contin Educ Pract Vet 1996;18:381-391

2. Johnson JA, Austin C, Breur GJ. Incidence of canine appendicular musculoskeletal disorders in 16 veterinary teaching hospitals from 1980 through 1989. Vet Comp Orthop Traumatol 1994;7:56-69

3. Lampman TJ, Lund EM, Lipowitz AJ. Cranial cruciate disease: current status of diagnosis, surgery, and risk of disease. Vet Comp Orthop Traumatol 2003;16:122-126

4. Arnoczky SP: Pathomechanics of cruciate ligament and meniscal injuries. In: Bojrab MJ ed. Disease Mechanisms in Small Animal Surgery. Philadelphia, Lea \& Febiger, 1993;764-777 
5. Korvick DL, Pijanowski GJ, Schaeffer DJ. Three-dimensional kinematics of the intact and cranial cruciate ligament-deficient stifle of dogs. J Biomech 1994;27:77-87

6. Tepic S, Damur D, Montavon PM. Biomechanics of the Stifle Joint. $1^{\text {st }}$ World Orthopedic Veterinary Congress, Munich, Germany, 2002 (abstract), pg 189-190

7. Johnson JM, Johnson AL. Cranial cruciate ligament rupture. Pathogenesis, diagnosis, and postoperative rehabilitation. Vet Clin North Am 1993;23:717-733

8. Slocum B, Slocum TD. Tibial plateau leveling osteotomy for repair of cranial cruciate ligament rupture in the canine. Vet Clin North Am $1993 ; 23: 777-795$

9. Priddy NH, Tomlinson JL, Dodam JR. Complications with and owner assessment of the outcome of tibial plateau leveling osteotomy for treatment of cranial cruciate ligament rupture in dogs:193 cases (19972001). J Am Vet Med Assoc 2003;222:1726-1732 
10. Slocum B, Devine T. Cranial tibial wedge osteotomy: a technique for eliminating cranial tibial thrust in cranial cruciate ligament repair. J Am Vet Med Assoc 1984;184(5):564-569

11. Innes JF, Barr ARS. Can owners assess outcome following treatment of canine cruciate ligament deficiency? J Small Anim Prac 1998;39:373378

12. Pacchiana PD, Morris E, Gillings SL, et al. Surgical and postoperative complications associated with tibial plateau leveling osteotomy in dogs with cranial cruciate ligament rupture:397 cases (1998-2001). J Am Vet Med Assoc 2003;222:184-193

13. Rayward RM, Thomson DG, Davies JV, et al. Progression of osteoarthritis following TPLO surgery: a prospective radiographic study of 40 dogs. J Small Anim Prac 2004;45:92-97

14. Montavon PM, Damur DM, Tepic S. Advancement of the tibial tuberosity for the treatment of cranial cruciate deficient canine stifle. $1^{\text {st }}$ World Orthopedic Veterinary Congress, Munich, Germany, 2002 (abstract), pg 152 
15. Montavon PM, Damur DM, Tepic S. Tibial tuberosity advancement (TTA) for the treatment of cranial cruciate disease in dogs: evidences, technique and initial clinical results. $12^{\text {th }}$ ESVOT Congress 2004:254255

16. Tepic S, Montavon PM. Is cranial tibial advancement relevant in the cruciate deficient stifle? $12^{\text {th }}$ ESVOT Congress 2004:132-133

17. Maquet P. Tibial tuberosity advancement. Clin Orth Rel Res 115:225230, 1976

18. Nisell R. Mechanics of the knee. A study of joint and muscle load with clinical applications. Acta Orth Scan Supp 56(216):3-42, 1985

19. Giffen JR, Vogrin TM, Zantop T, et al. Effects of increasing tibial slope on the biomechanics of the knee. Am J Sports Med 32:376-382, 2004

20. Boudrieaux R. Tibial plateau leveling osteotomy or tibial tuberosity advancement? Vet Surg 38:1-22, 2009 
21. Li G, Rudy TW, Allen C, et al. Effect of combined axial compressive and anterior tibial loads on in situ forces in the anterior cruciate ligament: a porcine model. J Orthop Res 16:122-127, 1998

22. Nisell R, Ericson MO, Nemeth G, et al. Tibiofemoral joint forces during isokinetic knee extension. Am J Sports Med 17:49-54, 1989

23. Shirazi-Adl A, Mesfar W. Effect of tibial tubercle elevation on biomechanics of the entire knee joint under muscle loads. Clin Biomech 22:344-351, 2007

24. Nakamura N, Ellis M, Seedhom BB. Advancement of the tibial tuberosity: a biomechanical study. J Bone Joint Surg 67-B(2):255-260, 1985

25. Montavon PM. Tibial tuberosity advancement: biomechanics and surgical procedure. Proceedings of the 2005 ACVS Veterinary Symposium, 2005 (abstract), pg 438-440 
26. Apelt D, Kowaleski M, Boudrieau RJ. Effect of tibial tuberosity advancement on cranial tibial subluxation in canine cranial cruciatedeficient stifle joints: an in vitro experimental study. Vet Surg 36:170177,2007

27. Kipfer NM, Damur DM, Guerrero T, et al. Effect of tibial tuberosity advancement on femorotibial shear in cranial cruciate-deficient stifles: an in vitro study. Vet Comp Orthop Traumatol 21(5):385-390, 2008

28. Miller JM, Shires PK, Lanz OI, et al. Effect of 9mm tibial tuberosity advancement on cranial tibial translation in the canine cranial cruciate ligament-deficient stifle. Vet Surg 36:335-340, 2007

29. Wilke VL, Conzemius MG, Besancon MF, et al. Comparison of Tibial Plateau Angle between Clinically Normal Greyhounds and Labrador Retrievers with and without Rupture of the Cranial Cruciate Ligament. J Am Vet Med Assoc 2002;221:1426-1429

30. Morris E, Lipowitz AJ. Comparison of Tibial Plateau Angles in Dogs with and without Cranial Cruciate Ligament Injuries. J Am Vet Med Assoc 2001;218:363-366 
31. Kim SE, Pozzi A, Banks SA, et al. Effect of tibial tuberosity advancement on femorotibial contact mechanics and stifle kinematics. Vet Surg 38:33-39, 2009

32. Hoffmann DE, Miller JM, Ober CP, et al. Tibial tuberosity advancement in 65 canine stifles. Vet Comp Orthop Traumatol 19(4):219-227, 2006

33. Lafaver S, Miller NA, Stubbs WP, et al. Tibial tuberosity advancement for stabilization of the canine cranial cruciate ligamentdeficient stifle joint: surgical technique, early results and complication in 101 dogs. Vet Surg 36:573-586, 2007

34. Stein S, Schmoekel H. Short-term and eight to 12 months results of a tibial tuberosity advancement as treatment of canine cranial cruciate ligament damage. J Sm Anim Pract 49:398-404, 2008

35. Dennler R, Kipfer NM, Tepic S, et al. Inclination of the patellar ligament in relation to flexion angle in stifle joints of dogs without degenerative joint disease. Am J Vet Res 67(11):1849-1854, 2006 
36. Schwandt CS, Bohorquez-Vanelli A, Tepic S, et al. Angle between the patellar ligament and the tibial plateau in dogs with partial rupture of the cranial cruciate ligament. Am J Vet Res 67(11):1855-1860, 2006

37. Hottinger HA, DeCamp CE, Olivier NB, et al. Non-invasive kinematic analysis of the walk in healthy large-breed dogs. Am J Vet Res 57(3):381-388, 1996

38. Shahar R, Banks-Sills L. A quasi-static three-dimensional, mathematical, three-body segment model of the canine knee. J Biomech 37:1849-1859, 2004

39. Holden JP, Grood ES, Korvick DL, et al. In vivo forces in the anterior cruciate ligament: direct measurements during walking and trotting in a quadruped. J Biomech 27(5):517-526, 1994

40. Burns CG, Boudrieau RJ. Modified tibial tuberosity advancement procedure with tuberosity advancement in excess of $12 \mathrm{~mm}$ in four large breed dogs with cranial cruciate ligament-deficient joints. Vet Comp Orthop Traumatol 21:250-255, 2008 